\title{
An unexpected case of recurrence of pulmonary embolism in a patient recovered from COVID19 in full regimen dose of direct oral anticoagulant drug
}

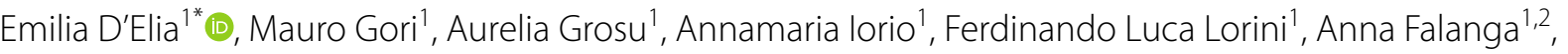
Fabiano Di Marco ${ }^{1,3}$ and Michele Senni ${ }^{1}$

\begin{abstract} bolic complications once healed after COVID-19. anticoagulation (DOAC), massive recurrent PE was diagnosed. patients.

\section{Background}

Severe acute respiratory syndrome coronavirus 2 (SARSCoV-2) caused by COVID-19 is a pandemic affecting all countries in the world [1]. Bergamo, Italy, has been particularly afflicted by this pandemic, earning the sad record of the city with the highest mortality in the world. Fortunately, the peak phase has passed, and we are almost back to normality. If on the one hand it is reassuring that new cases are decreasing, and the patients recovered are clearly increasing, on the other hand it is worrisome to assist to unexpected medium-term complications.
\end{abstract}

Background: Coronavirus Disease 2019 (COVID-19) is a pandemic affecting all countries in the world. Italy has been particularly afflicted by the health emergency, and since the peak phase has passed, major concern regarding medium to long term complications due to COVID-19 is arising. Little is known in literature regarding thromboem-

Case presentation: A 51-year-old patient recovered from COVID-19 pneumonia complicated by pulmonary embolism (PE) came to the hospital for palpitations and chest pain. Although he was on treatment dose of direct oral

Conclusion: In the early post COVID-19 era, the question remains regarding the efficacy of DOACs in COVID-19

Keywords: COVID-19, Pulmonary Embolism, Complications, Direct Oral Anticoagulation, Case Report

\footnotetext{
*Correspondence: edelia@asst-pg23.it

1 Cardiovascular Department, Hospital Papa Giovanni XXIII, Piazza OMS 1, Bergamo, Italy

Full list of author information is available at the end of the article
}

\section{Case presentation}

On April 29, 2020, a 51-year-old man presented to the Emergency Room (ER) with palpitations and chest pain. He was in a rehabilitation center after being discharged five days earlier from the hospital, where he had been hospitalized for COVID-19 pneumonia, complicated by right PE. He was initially treated with unfractionated heparin (UFH) and warfarin, and, once improved and hemodynamically stable, warfarin was replaced with dabigatran $150 \mathrm{mg}$ twice a day. After three consecutive negative COVID-19 swabs, the patient was discharged on curative regimen of DOAC. In addition to dabigatran, his therapy included betablockers, corticosteroids, levothyroxine, benzodiazepines.

Examination findings at that ER admission were as follows: blood pressure (BP) $90 / 60 \mathrm{mmHg}$, heart rate 97 beats/min, respiratory rate 20 breaths/min, temperature 
$37.1{ }^{\circ} \mathrm{C}$, normal oxygen saturation $(\mathrm{SaO} 2)$ on room air. On physical examination, he had an irregularly irregular heart rate, normally transmitted vesicular murmur, no findings suggestive for heart failure (HF). The electrocardiogram (ECG) showed atrial fibrillation, and intravenous amiodarone bolus plus infusion was started. Suddenly, he started to complain shortness of breath. He was found to be in respiratory distress, with hypotension (BP 85/55 $\mathrm{mmHg}$ ) and $\mathrm{SaO} 285 \%$. Oxygen $4 \mathrm{l} /$ min was placed and, due to persistent desaturation, nonrebreather oxygen mask ( $15 \mathrm{l} / \mathrm{min})$ was started.

Laboratory investigation revealed an increase of highsensitive troponin $(90 \mathrm{ng} / \mathrm{L}$, normal range $<54 \mathrm{ng} / \mathrm{L})$, an elevated D-Dimer $(3499 \mathrm{ng} / \mathrm{ml})$, an increase of the white blood cell count $(26,000)$, and a normal C-reactive protein $(0.2 \mathrm{mg} / \mathrm{L})$. Chest $\mathrm{x}$-ray showed bilateral interstitial infiltrates with accentuation of the vascular plot, in the absence of pleural effusion (Fig. 1). Arterial blood gas at the time of the onset of dyspnea showed PH 7.38, $\mathrm{PaCO}_{2}$ $22 \mathrm{mmHg}, \mathrm{PaO}_{2} 48 \mathrm{mmHg}$, and bicarbonate $20 \mathrm{mmol} / \mathrm{L}$. A reservoir $15 \mathrm{l} / \mathrm{min}$ was placed. On $70 \% \mathrm{FiO}_{2}$, arterial blood gas showed $\mathrm{PH} 7.44, \mathrm{PaCO}_{2} 37.8 \mathrm{mmHg}$, $\mathrm{PaO}_{2} 151 \mathrm{mmHg}$, and bicarbonate $16 \mathrm{mmol} / \mathrm{L}$. An ECG showed a tachycardia, with a new onset right bundle branch block, S1, and Q3. At the transthoracic echocardiography, right-sided chambers were severely dilated. Due to the sudden clinical deterioration, thrombolysis with tissue plasminogen activator (tPA) was immediately performed in the suspicion of recurrent PE. The patient had a rapid beneficial effect with restoration of stable hemodynamic parameters.

After infusion of tPA, a computed tomography angiogram was performed, which documented marked defect of endoluminal filling of the right and left pulmonary artery with extension to their main branches referable to

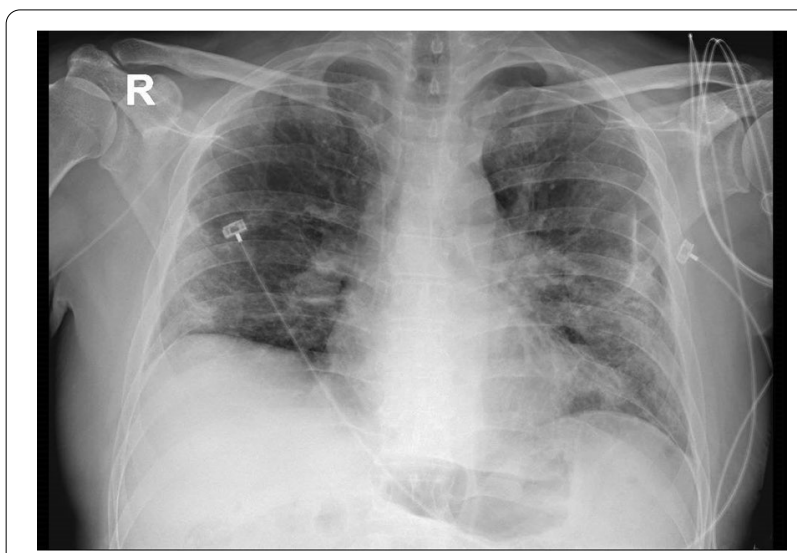

Fig. 1 Chest $X$ Ray showing bilateral interstitial infiltrates with accentuation of the vascular plot, in the absence of pleural effusion acute PE, more extensive than the previous one (Fig. 2). The patient was than admitted to the Intensive Care Unit and UFH was started intravenously. During the inhospital stay, the patient remained hemodynamically stable, in sinus rhythm, and apyretic. His COVID19 swab test resulted negative. To exclude venous thromboembolism (VTE), a venous echo-Doppler ultrasound was performed, which resulted negative. After collegial discussion, it was decided to continue for one month with LMWH and then, if there will be more clearer data on the matter, to start warfarin.

\section{Discussion}

Reports of acute PE associated with COVID-19 have emerged more and more in the literature [2-5], and frequency of PE in the COVID-19 era seems to be extremely higher than that in the same control period of 2019 [6]. Nearly $20 \%$ of COVID- 19 patients present with severe coagulation abnormalities, which may occur in almost all of the critically ill COVID-19 cases, and can negatively affect prognosis. It has also been reported that markedly

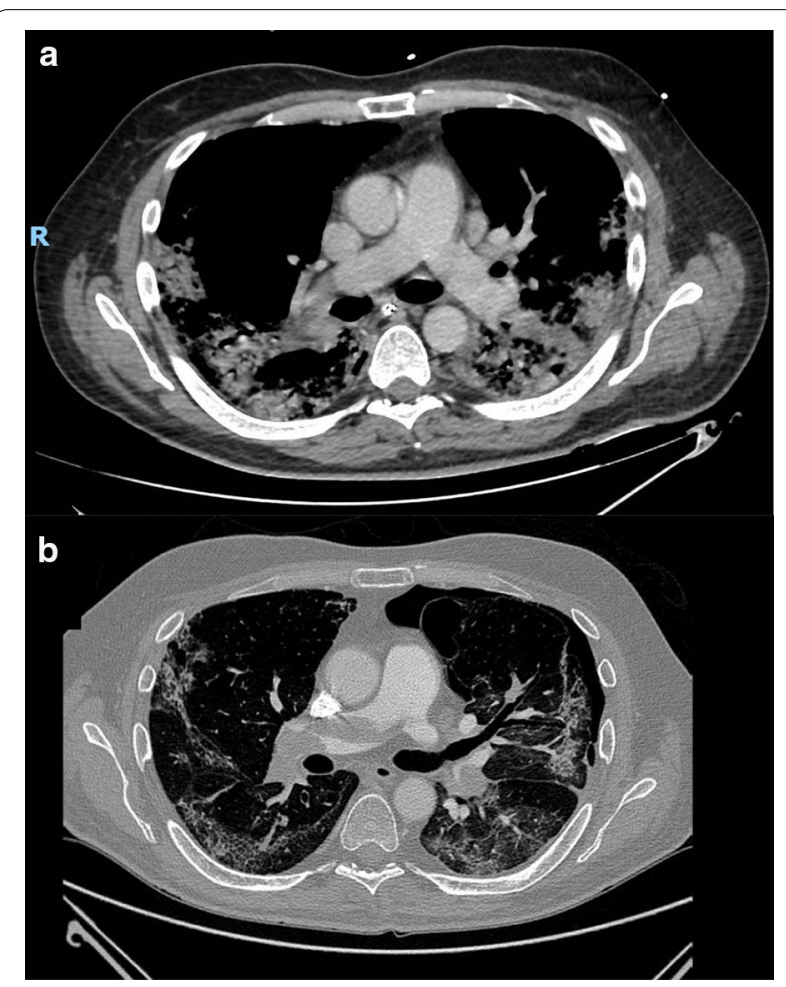

Fig. 2 Computed tomography angiogram during the first hospital admission showing a focal filling defect affecting the pulmonary artery branch for the lower right lobe with thromboembolic outbreak (a). Computed tomography angiogram at the time of hospital re-admission showing extensive defect of endoluminal filling of the right and left pulmonary artery with extension to their main branches (b) 
elevated D-dimer, fibrinogen degradation products and prothrombin were very common in COVID-19-related deaths $[7,8]$. Mini autopsies have shown microthrombi in lungs, in liver, and in the entire vascular system, suggesting that severe endothelial dysfunction, driven by the cytokine storm and induced by hypoxemia, leads to disseminated intravascular coagulation, causing thromboembolic complications [9]. However, in the early the post-COVID-19 era, there are no data regarding the likelihood of recurrent PE in healed COVID-19 patients, already on treatment dose anticoagulant therapy. Nowadays, in all severe COVID-19 patients and in those suspected for VTE, if there is no anticoagulation contraindication, it is suggested to start curative anticoagulant therapy. The first-line treatment is based on parenteral anticoagulation with low molecular weight heparin (LMWH), or UFH by venous infusion in case of severe renal impairment, with a regular monitoring for anticoagulation dose adjustment. The DOACs are an option only after the acute phase if the patient is more stable with no more treatment interfering with CYP3A4, and no major comorbidities [10].

As described in our case report, nonetheless, recurrence of PE can occur in the early post COVID-19 era despite curative regimen of DOACs. It is still not yet clear how to behave with the anticoagulation regimen to prevent these mid-term complications. Specifically, it remains to be clarified whether a strategy with LMWH embraced to warfarin is superior to the treatment dose of DOACs. Further randomized studies are needed to assess the best prophylaxis and treatment of this worrying condition $[11,12]$.

In conclusion, in the early post COIVD-19 discharge, it is of fundamental importance to recognize the mediumterm risk of thromboembolic complications, especially in the most critical patients. To this regard, it would be advisable to perform randomized clinical trials to demonstrate the best anticoagulant regimen to be dedicated to these patients.

\begin{abstract}
Abbreviations
COVID-19: Coronavirus Disease 2019; PE: Pulmonary embolism; DOAC: Direct oral anticoagulation; Sars-CoV-2: Severe acute respiratory syndrome coronavirus 2; ER: Emergency room; UFH: Unfractionated heparin; BP: Blood pressure; $\mathrm{SaO} 2$ : Oxygen saturation; HF: Heart failure; ECG: Electrocardiogram; tPA: Tissue plasminogen activator; VTE: Venous thromboembolism; LMWH: Low molecular weight heparin
\end{abstract}

\section{Acknowledgements}

Not applicable.

\section{Authors' contributions}

ED treated the patient in the cardiology ward, developed the idea of writing the case and substantially wrote the manuscript. MG, FDM, FLL, AF, MS revised the manuscript. AG, Al treated the patient in the cardiology ward and help in writing the case. All authors read and approved the final manuscript.
Funding

No specific funding was received from any bodies in the public, commercial or not-for-profit sectors to carry out the work described in this manuscript.

Availability of data and materials

Data of the patient available from the corresponding author.

\section{Declarations}

\section{Ethical approval and consent to participate}

Not applicable.

\section{Consent for publication}

Written informed consent was obtained from the patient for publication of this Case Report and any accompanying images. A copy of the written consent is available for review by the Editor of this journal.

\section{Competing interests}

The authors have declared no conflicts of interest. Prof Fabiano di Marco is member of the editorial board for the BMC Pulmonary Medicine.

\section{Author details}

${ }^{1}$ Cardiovascular Department, Hospital Papa Giovanni XXIII, Piazza OMS 1, Bergamo, Italy. ${ }^{2}$ Department of Medicine and Surgery, University of Milan, Milan, Italy. ${ }^{3}$ Department of Health Sciences, University of Milan, Milan, Italy.

Received: 13 June 2020 Accepted: 2 March 2021

Published online: 24 March 2021

\section{References}

1. Huang C, Wang Y, Li X, et al. Clinical features of patients infected with 2019 novel coronavirus in Wuhan China. Lancet. 2020;395:497-506.

2. Brüggemann R, Gietema H, Jallah B, Ten Cate H, Stehouwer C, Spaetgens $B$. Arterial and venous thromboembolic disease in a patient with COVID-19: a case report. Thromb Res. 2020;S0049-3848(20):30163-8. https://doi.org/10.1016/j.thromres.2020.04.046.

3. Chen N, Zhou M, Dong X, et al. Epidemiological and clinical characteristics of 99 cases of 2019 novel coronavirus pneumonia in Wuhan, China: a descriptive study. Lancet. 2020;395:507-13.

4. Ullah W, Saeed R, Sarwar U, Patel R, Fischman DL. COVID-19 complicated by Acute pulmonary embolism and right-sided heart failure. JACC Case Reports 2020 Apr 17 doi: https://doi.org/https://doi. org/10.1016/j.jaccas.2020.04.008 (in press)

5. Polat $\mathrm{V}$, Bostanci GI. Sudden death due to acute pulmonary embolism in a young woman with COVID-19. J Thromb Thrombolysis. 2020;11:13. https://doi.org/10.1007/s11239-020-02132-5(inpress).

6. Poissy J, Goutay J, Caplan M et al. Lille ICU Haemostasis COVID19 group. Pulmonary embolism in COVID-19 patients: awareness of an increased prevalence. Circulation 2020 Apr 24 doi: https://doi. org/10.1161/CIRCULATIONAHA.120.047430 (in press)

7. Tang N, Li D, Wang X, Sun Z. Abnormal coagulation parameters are associated with poor prognosis in patients with novel coronavirus pneumonia. J Thromb Haemost. 2020;18:844-7.

8. Lippi G, Favaloro E. D-dimer is associated with severity of coronavirus disease 2019: a pooled analysis. J Thromb Haemost. 2020. https://doi. org/10.1055/s-0040-1709650(inpress).

9. Konstantinides SV, Meyer G, Becattini C. et al. ESC Scientific Document Group. 2019 ESC Guidelines for the diagnosis and management of acute pulmonary embolism developed in collaboration with the European Respiratory Society (ERS). Eur Heart J 2020; 41: 543-603

10. Zhai Z, Li C, Chen Y, Gerotziafas G. Prevention and treatment of venous thromboembolism associated with Coronavirus disease 2019 Infection: a consensus statement before guidelines. Thromb Haemost. 2020. https://doi.org/10.1055/s-0040-1710019(inpress).

11. Gris JC, Perez-Martin A, Quéré I, Sotto A. COVID-19 associated coagulopathy: The crowning glory of thrombo-inflammation concept. Anaesth Crit Care Pain Med 2020;39:381-382. doi: https://doi. org/10.1016/j.accpm.2020.04.013. 
12. Iba T, Levy JH, Connors JM, Warkentin TE, Thachil J, Levi M. The unique characteristics of COVID-19 coagulopathy. Crit Care 2020;24:360. https:// doi.org/10.1186/s13054-020-03077-0.

\section{Publisher's Note}

Springer Nature remains neutral with regard to jurisdictional claims in published maps and institutional affiliations.

- fast, convenient online submission

- thorough peer review by experienced researchers in your field

- rapid publication on acceptance

- support for research data, including large and complex data types

- gold Open Access which fosters wider collaboration and increased citations

- maximum visibility for your research: over $100 \mathrm{M}$ website views per year

At BMC, research is always in progress.

Learn more biomedcentral.com/submissions 